\title{
WHAT EMPOWERS OR DISEMPOWERS SIKH WOMEN AFTER MIGRATING TO ONTARIO, CANADA?
}

\author{
by
}

Rajinder Kaur Virk, B.Sc, Panjab University (2000), M.A, Panjab University (2002) BSW, University of Victoria (2016)

\author{
An MRP \\ presented to Ryerson University \\ in partial fulfillment of the \\ requirements for the degree of \\ Master of Social Work \\ in the Program of \\ Social Work
}

Toronto, Ontario, Canada, 2017

(C) Rajinder Kaur Virk 2017 


\section{AUTHOR'S DECLARATION FOR ELECTRONIC SUBMISSION OF A MRP}

I hereby declare that I am the sole author of this MRP. This is a true copy of the MRP, including any required final revisions.

I authorize Ryerson University to lend this MRP to other institutions or individuals for the purpose of scholarly research

I further authorize Ryerson University to reproduce this MRP by photocopying or by other means, in total or in part, at the request of other institutions or individuals for the purpose of scholarly research.

I understand that my MRP may be made electronically available to the public. 


ABSTRACT
What empowers or disempowers Sikh women after migratial Work, 2017
Master of Social
Rajinder Kaur Virk
Program of Social Work,
Ryerson University

Sikh women are known for their valour and bravery in India. But many negative stereotypes are attached to their identity in Canada. They are often labelled as submissive and docile. This research has focused on empowering and disempowering factors experienced by Sikh women in Ontario, Canada. There is a substantial amount of literature on South Asian women's experiences but there is a lack of literature, particularly focusing on Sikh women's empowerment. In this study in person interviews were conducted with three Sikh women who were between the ages of 30-40 years and have immigrated to Canada from Punjab, India and have lived in Ontario for five years or more. Qualitative research was conducted using a narrative methodology. Recruitment emails were used to select study participants. The goal of this research is to add to existing social work literature. Findings will aid settlement agencies in understanding the needs of Sikh women, after they migrate to Canada and what challenges are faced by them. This, in turn, will help settlement workers to provide culturally competent support to Sikh women. This study will also help challenge some of the negative myths about Sikh women. 


\section{ACKNOWLEDGEMENTS}

I would like to thank my senior supervisor, Samantha Wehbi for her advice, expertise, support and encouragement throughout our work together. I am truly grateful for all the time and effort that Samantha has invested in my learning, development, and success.

Special thanks to my MRP group for their valuable feedback, suggestions, and support. 


\section{DEDICATION}

I dedicate this research to all the participants who have taken time out of their lives to share their experiences with me. I also dedicate this research to my parents whose words and advice gave me strength to pass through the tough times of juggling between jobs, studies and kids; and my son and daughter who were patient enough and understood when I was not able to spend as much time with them as a family due to studies. 


\section{TABLE OF CONTENTS}

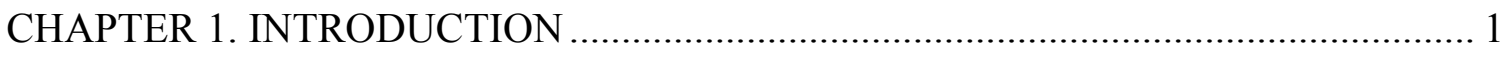

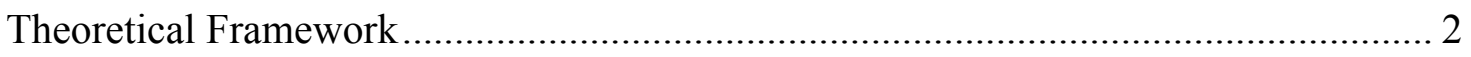

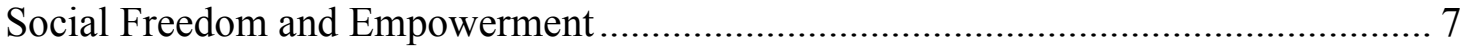

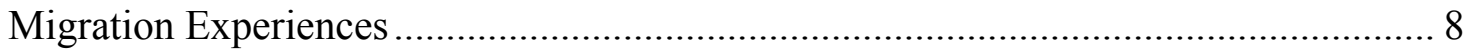

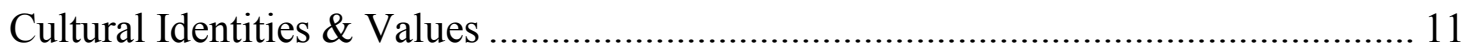

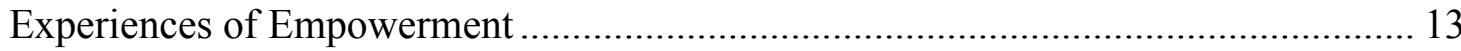

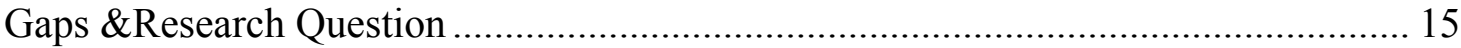

CHAPTER 3. RESEARCH DESIGN ................................................................ 17

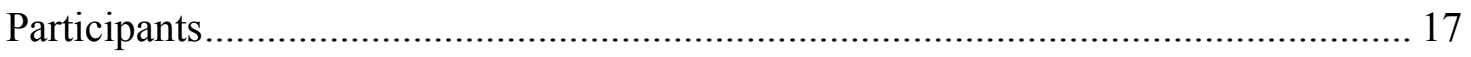

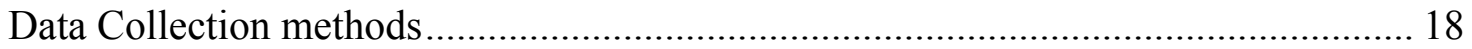

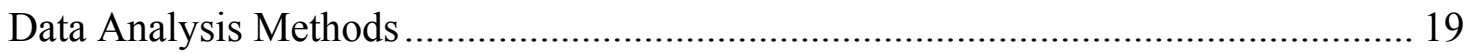

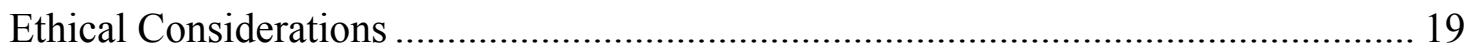

CHAPTER 4. FINDINGS AND DISCUSSION …...................................................... 22

Language Experiences \& Struggles with Recognition of Foreign Educational

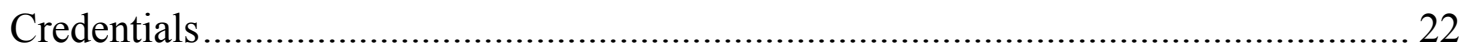

The New Educational Environment........................................................................... 25

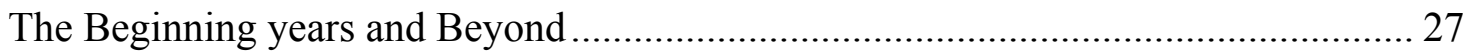

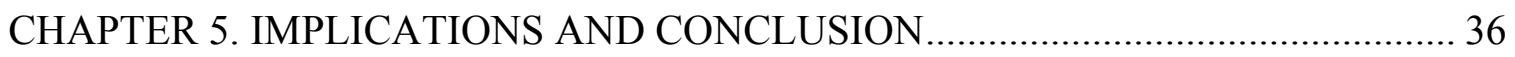

Implications for Social Work Practice .................................................................... 36

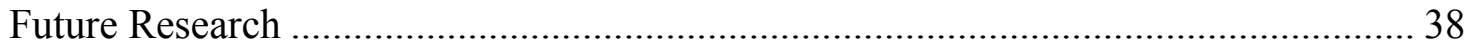

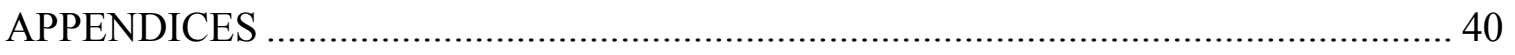

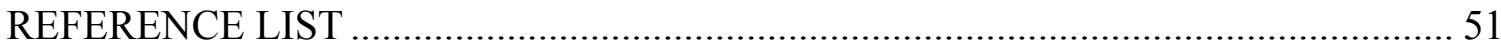




\section{LIST OF APPENDICES}

Appendix A - Recruitment E-mail $\ldots \ldots \ldots \ldots \ldots \ldots \ldots \ldots \ldots \ldots \ldots \ldots \ldots \ldots \ldots \ldots \ldots \ldots \ldots . \ldots \ldots$

Appendix B - Consent Form..............................................42

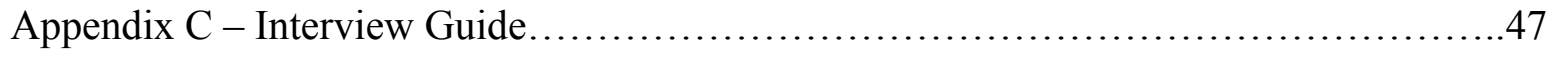

Appendix D - Resources for Participants.........................................48

Appendix E - Ethics Clearance Certificate.....................................50 


\section{CHAPTER 1. INTRODUCTION}

A large number of Sikh immigrant women reside in Canada. The concern is that very few studies exist which look particularly into the settlement experiences of Sikh women. The purpose of this research is to look into what makes these women feel empowered or disempowered after immigration to Canada. Research is done in India by Amin (2004) and Gupta and Yesudian (2006) informs us about this aspect of Sikh women's identity, but no such research exists in Ontario. The aim of this research is to address this gap in knowledge. This research will seek to understand disempowerment barriers and stereotypes that Sikh women are weak and suppressed by men in their community. The study would be of great use to settlement workers and will inform them on how to provide culturally competent support to Sikh immigrant women.

The Majority of Sikh women come to Canada under the dependent category, either as dependents of their spouse, their parents or their children. Negative stereotypes are particularly attached to South Asian women who come to Canada under the dependent category. They are perceived as being docile and suppressed by patriarchal norms (Abraham, 2000; Ahmad, Driver, McNally \& Stewart, 2009; Alaggia, Regehr \& Rishchynski, 2009; Anitha, 2011; Dalal, 2011; Walton-Roberts, 2007).

No research has been conducted on Sikh women in Ontario reporting on their empowerment. It is important to conduct research in Ontario as there are Sikh women who live here and such labels affect their identity and demean their strength. Being a Sikh woman myself, who immigrated to Ontario, Canada as a dependent on my spouse, I do not agree nor identify with these labels. I feel research needs to be conducted to explore other Sikh women's perspectives on empowerment. 
Sikh women, since Sikhism began in the fifteenth century, have been considered equal to men. For example, in Sikhism, there is the prevalence of gender neutral names. A Sikh woman can be given the same name given to a man. Sikh women were never considered any less than Sikh men and were not considered docile or weak as they fought in many battles against foreign invaders of Punjab (Singh, 2004). Even research conducted by Amin (2004), Gupta and Yesudian, (2006) indicates Sikh women rate pretty high on empowerment and social freedom indexes. These two indexes were used to measure the empowerment of Sikh women in comparison to other women of India. Given this, why are they perceived as weak in the Western world? This is a question that I aim to challenge in this MRP as I focus on Sikh women's experiences of empowerment in the Ontario context.

The contributions of this MRP study for social work consist of adding to existing social work literature; and helping to challenge some of the negative myths about Sikh women. Findings will aid settlement agencies in understanding the needs of Sikh women, after they migrate to Canada and what challenges are faced by them. This, in turn, will help settlement workers to provide culturally competent support to Sikh women.

\section{Theoretical Framework}

This study is guided by postcolonial and transnational feminist frameworks, discussed in this section. Before proceeding further into the discussion, it is important to understand what empowerment means in context to this research. Kaur (2004) notes the difficulty in defining empowerment, as different individuals might perceive empowerment differently based on their socio-cultural background and values. Stromquist (as cited in Kaur, 2004) define it as:

Empowerment in its emancipatory meaning, is a serious word--one which brings up the question of personal agency rather than reliance on intermediaries, one that links action to 
needs, and one that results in making significant collective change. It is also a concept that does not merely concern personal identity but brings out a broader analysis of human rights and social justice (p.7).

Thus in this study, I understand empowerment both from the lens of control that women have over their lives in interpersonal relations; as well as control over their lives when they function outside their homes in larger institutions in society such as workplaces. The second definition of empowerment focuses more at an individual level and is seen as, "the ability to direct and control one's own life" (Aksornkool, 1993 as cited in Kaur, 2004, p. 5). Hence, in order for us to better understand how Sikh women's experiences of empowerment are affected by migration, it is essential to understand the overall picture of how much control Sikh women have over their lives in their homes and in the outside world.

In studying Sikh women's experiences, another phenomenon which has to be examined is how gender and race affect their experiences in Canada. Given this, it becomes important to learn about Sikh women's empowerment from the lens of transnational feminism and postcolonial feminism. Postcolonial feminist theories show how colonialism and racism have affected the lives of non-white women at social, economic and political levels and still continue to do so. The concern is that women coming from the South Asian continent and other global South countries are often seen as docile and stereotyped as dependents by western feminist scholars.

Mohanty (1988) a key postcolonial scholar critiques western feminist scholarship and colonial discourses about third world country women. Mohanty shares how third world country women get categorized as "homogenous powerless group" who are often assumed to be victims of "particular cultural and socio-economic systems" (p.66). 
Mohanty (1988) further argues how assumptions are made about third world women:

This average third world woman leads an essentially truncated life based on her feminine gender (read: sexually constrained) and religious domesticated, family oriented, victimized, etc.) This I suggest is in contrast to the (implicit) self-representation of western women as educated, modern as having control over their own bodies and sexualities, and the 'freedom to make their own decisions. (p. 65)

Through Feminist Postcolonial Theory, Mohanty challenges this preconceived notion about third world women; such notions cause great harm to the identity of third world women. Sikh women have been identified in this manner and often get categorized in a similar way by western researchers. Hence it is important to look at the life experiences of Sikh women from a Post Colonial Theory standpoint. These life experiences will provide us a deeper understanding about the reality of empowering and disempowering factors in the lives of Sikh women. It will also help us to dismantle assumptions about Sikh women.

Mohanty (2003) in her book "Feminism Without Borders" argues that western feminists portray global South women as 'victims of male violence' and 'religious ideologies'. What western scholars fail to understand is that the priorities and expectations of women from the global South are affected by their socio-cultural background. What might be important to white western women might not hold any significance for women from different racial backgrounds. A woman's experience can't be separated from her racial identity and how it affects her life. Mohanty (2006) argues that descriptions of non-white women by western scholars produces a 
'third world difference' (p.80) and reproduces the inferiority of global South women in comparison to white western women. Postcolonial feminism as discussed by Mohanty (2003) helps in this research by raising awareness that, "being a woman has political consequences in the world we live in; that there can be unjust and unfair effects on women depending on our economic and social marginality and/or privilege" (p.3).

Another theory which is vital for this research and must be taken into consideration is transnational feminism. According to Grewal and Kaplan (1994), transnational feminism emphasizes the role of gender and race in resisting patriarchal and capitalist power. Grewal and Kaplan note that transnational feminist paradigms draw from postcolonial feminist theories. Grewal and Kaplan(2000) share how transnational feminism helps them to examine various forms of movement and displacements in current eras such experienced by immigrants, refugees and people traveling for education and business purposes. This analysis helps in learning, "how inequalities of class,gender, nationality, sexuality, and ethnicity are created through movements over time and space in particular ways" (p.1).Thus, it becomes important to understand how Sikh women are affected by race, gender and colonialism under a transnational and postcolonial feminist framework. These are the lenses I carry forward throughout the MRP as I discuss the literature as well as my study findings and implications for social work. 


\section{CHAPTER 2. LITERATURE REVIEW}

I conducted an in-depth review of the scholarship to comprehend research which exists on Sikh women. The main purpose of the literature review was to research factors which impact empowerment of Sikh women after migration. I consulted the databases such as social work abstract and social service abstracts and read journal articles from these databases. There has been a substantial amount of research done in Australia, India, United Kingdom, United States

and Sweden about Sikh women, but little scholarship exists which addresses the identity of Sikh women in Canada. The main issues of settlement experiences, domestic violence, patriarchal norms, social isolation, racism, discrimination and empowerment emerged from the literature reviewed.

Four major themes stood out of the literature review. First, Sikh women demonstrate a high degree of social freedom and rate fairly high in empowerment (Amin, 2014; Gupta \& Yesudian, 2006). Second, migration to a new country presents several challenging factors such as social isolation, language barriers, domestic violence, racism and discrimination (Abraham, 2000; Ahmad, Driver, McNally, \& Stewart, 2009; Alaggia, Regehr, \& Rishchynski, 2009; Anitha, 2011; Dalal, 2011; Walton-Roberts, 2007). Third, Sikh women who migrate at a later stage of life stick strongly to their cultural identity and traditional healing methods $(\mathrm{Ng} \&$ Northcott, 2009; Grewal, 2008). The final theme is that Sikh women use economic opportunities, industrial actions and transnational relationships effectively (Anitha, Pearson, \& McDowell, 2012; Burholt \& Wenger, 2004; Costa-Pinto, 2010; Pratt \& Walton-Roberts, 2005; Sodhi, 2007). Sikh women effectively utilize advance technologies, mobile modernities and bicultural identities to feel empowered. 


\section{Social Freedom and Empowerment}

This literature review will first explore Sikh women's experiences in terms of empowerment in their country of origin before migrating to Canada. The research conducted by Amin (2014) and Gupta and Yesudian (2006) sheds some light on Sikh women's empowerment and social freedom in Punjab, India. Amin (2014) defines social freedom as, “women's desire to be free from social taboos, conventions, rituals and roles which provide them with lower status in society" (p. 745). Empowerment in this study was defined as, "the process, and the outcome of the process, by which women gain greater control over material and intellectual resources, and challenge the ideology of patriarchy and gender-based discrimination against women" (Batliwala, 1995 as cited in Gupta \& Yesudian, p. 366). In the context of these definitions, Sikh women show a high rate of empowerment and social freedom (Amin, 2004; Gupta \& Yesudian, 2006). Higher education and having employment have been noted to play an important role in increasing empowerment for Sikh women. Amin (2004) shares that urban or rural location makes no difference in empowerment experiences of Sikh women.

The studies by Amin (2004), and Gupta and Yesudian (2006) focused on quantitative methods of data collection; hence, the important life experiences of these women are missing in these studies. Both researchers failed to provide enough account of why certain ethnic background women feel more disempowered in comparison to others. Further exploration could be done by taking into account the life stories of women in the context of race and religion. It is noteworthy that if Sikh women were empowered in their country of origin what leads to them being seen as weak women, suppressed by patriarchal norms in the Western world? 
Keeping my aforementioned theoretical framework in mind is important here to help understand this discrepancy. Moreover, I reviewed the empirical literature from the Western world to learn further about this stereotype attached to Sikh women's identity.

\section{Migration Experiences}

Research studies conducted by Abraham, Ahmad, Driver, McNally and Stewart (2009), Alaggia, Regehr and Rishchynski (2009), Anitha (2011), Dalal (2011) and Walton-Roberts (2007) discuss the disempowering factors in the lives of South Asian women (SAW). All these studies were chosen for this literature review due to the presence of Sikh women participants. These studies describe similarities of SAW's experiences including domestic violence, language barriers, racism, discrimination, social isolation and oppressive immigration policies. All these factors are seen to lead to disempowerment of SAW in the Western world.

The economic empowerment of migrant Sikh women was explored in several studies with slightly different results. Dalal (2011) concluded that the economic empowerment of South Asian women does not necessarily protect them from intimate partner violence. However, similar to Amin (2004) and Gupta and Yesudian (2006),Dalal (2011) found Sikh women experience less intimate partner violence in comparison to women of other religious backgrounds in India. Dalal (2011) summarized that economic empowerment did not make much difference and Gupta and Yesudian (2006) stated that women feel empowered when they have better financial stability.

Dalal's (2011) research was conducted in Sweden but the quantitative data utilized was taken from the Indian National Family Health Survey, conducted in India. This particular research presented a conflicting stance on the role of economic empowerment in the lives of SAW, in comparison to Amin, (2004) and Gupta and Yesudian's (2006) research. 
Dalal reported how higher rates of education along with economic empowerment better protect South Asian women from domestic violence. The remaining studies by Abraham, Ahmad, Driver, McNallyand Stewart (2009), Alaggia, Regehr and Rishchynski (2009), Anitha (2011) and Walton-Roberts (2007) concluded their findings based on data collected in Western countries. The majority of respondents in these studies are South Asian women between the ages of 18-68 who had immigrated to Western countries under the spousal sponsorship category. Another common theme related to migrant SAW in the studies by Abraham, Ahmad, Driver, McNally and Stewart (2009), Alaggia, Regehr and Rishchynski (2009), Anitha (2011), Dalal (2011) and Walton-Roberts (2007) is that all women report feelings of social isolation. This isolation is felt due to leavingbehind important friends and relatives in their originating country. This exclusion of valid relationships creates a power imbalance in their life and their abuse gets justified through patriarchal norms, as they experience spousal abuse with minimal other networks of support in their lives.

Ahmad et al., (2009) explained that prominent reasons against disclosure of violence and help-seeking were linked to, "the intertwined contextual factors of immigration and sociocultural norms, in particular patriarchy and elements of collectivism and families" (p. 619). The majority of SAW sought help only when abuse became extremely intolerable or when the safety of their children was jeopardized. Another similarity in these studies was seen in help-seeking patterns. These women sought assistance from their social networks first and then approached outside resources for help. 
Walton-Roberts' (2008) research focused on help-seeking patterns and importance of weak ties support (this is support provided by domestic violence agencies and other professionals) in the lives of Sikh women living in Squamish, British Columbia. Weak ties are shown to be highly resourceful for Sikh women in this study.

We cannot deny the importance of weak ties in SAW lives. But should be at the same time should be mindful of importance of strong ties which is the maternal family of SAW. The maternal family provides culturally appropriate support to women. Another drawback of the study is that the strong ties discussed focused mainly on relatives on the husband's side.

A common theme in the Western-based studies discussed in this section so far is the over-emphasis on reasons why SAW do not seek help; but none of these studies provide suggestions for how women can be made aware of supportive resources available to them. Hence the aim of researchers in these studies seems to be lost and it feels like a derogatory stance is being taken towards SAW and the South Asian community.

Alaggia et. al., (2009) and Anitha's (2011) research highlights how oppression faced by SAW women is not limited to their home environment, as oppressive immigration policies are another disempowering factor for SAW, whose sponsorship is voided due to marriage breakdown and loss of residency status. This is evident in Anitha's (2011) research which shines a light on how South Asian women in the UK usually get deported if their marriage falls apart, even when the reason for the breakdown is domestic violence. Alaggia et al.'s (2009) research presents a similar picture of oppressive immigration policies in Canada. Such oppressive immigration policies highlight the overt racism SAW face in the white-dominated context. 
Another important disempowering factor is language barriers. Alaggia, Regehr and Rishchynski (2009) share how language barrier causes isolation for SAW. One of the SAW narrative in their research highlights this for us, "If you don't know the language, it is difficult to adjust to everything” (p. 338) Language barrier creates hardships for Sikh women to find employment or in making new contacts. SAW usually get low paying jobs in general labor and have to work longer hours.

Even educated Sikh women have to do labor jobs as their education credentials are considered inferior to Western standards. Their experiences are further impacted negatively by racism experienced at workplaces.

An important limitation of the afore-mentioned studies is that women are often labeled as weak; the resistance of these women in abusive and discriminatory situations goes unnoticed. Moreover, researchers focused mainly on the experiences of married women who came under the sponsorship category. These studies fail to mention experiences of Sikh women who have been settled in Western Countries for longer periods of time and as well as experiences of Sikh women who migrate at a later stage of life as dependents on their children. Also important is the need to understand is how feelings of isolation are dealt with by Sikh women to feel empowered.

\section{Cultural Identities \& Values}

Research carried out by Ng and Northcott (2009) and Grewal (2008) focused on the experiences of senior Sikh women and other Sikh women who have been staying in western countries for a longer time. The study by $\mathrm{Ng}$ and Northcott (2009) was conducted in Edmonton, Alberta. This research focused on how the concept of "bicultural identity" and "strong transnational ties" helped senior immigrants to assimilate better into Canadian society ( $\mathrm{Ng} \&$ Northcott, 2009, p. 131). 
Grewal's (2008) study was conducted in the United States and its purpose was to inform service providers on how Punjabi women can be supported to seek medical help in addressing symptoms of depression, and also to learn about these women's coping strategies. Grewal's study challenges conceptions of stigma when seeking outside help. Sikh women in Grewal's study shared how spirituality and cultural values kept them strong even in adverse situations.

This positive emphasis on coping strategies through reliance on culture offers a contrast to the domestic violence studies discussed in the previous section of this literature review where cultural norms were seen as oppressive by nature.

Similarly, Ng and Northcott (2009) indicated seniors who maintained strong transnational ties kept their cultural identity intact and were more likely to develop English language proficiency and assimilated well in Canadian Society. SAW were found to be more strongly attached to their cultural identity than South Asian men. The researchers laid a strong emphasis on the importance of acquiring English language proficiency. Ng and Northcott's study seems to be problematic as the main focus is on finding out how well South Asian seniors adopt Canadian identity. From a critical perspective, why is retaining ethnic identity not given more importance? Yet again the resistance and empowerment of SAW after the migration is not given importance.

This theme from the literature still leaves a gap in knowledge in how Sikh women empower themselves in the western world. The next set of studies helps us to explore how Sikh women empower themselves after migration. The theme which emerges from the next set of empirical studies is that Sikh women effectively use employment opportunities, labor disputes, maintain transnational ties, utilize advanced technology, mobile modernity and bicultural identity to feel empowered (Anitha, Pearson,\& McDowell, 2012; Burholt \& Wenger, 2004; Costa-Pinto, 2010; Pratt \& Walton-Roberts, 2005; Sodhi, 2007). 


\section{Experiences of Empowerment}

The research by Anitha, Pearson, and McDowell (2012) focuses on narratives of two groups of SAW in the UK. These SAW women took part in industrial labor action and stood up for their rights and negotiated these rights through "classed, racialized, gendered inclusion in the labor market" (p. 754).

The industrial action taken by SAW did not provide much financial help but what it provided SAW was a strong will to fight injustices. Their actions served as inspirations for future generations of immigrant women and provided better future working conditions. Anitha, Pearson and McDowell's research helped to show how the racial identities of SAW intersect with their working lives. This study also brings to the forefront these women's own resistance and selfempowerment. The drawback of this study is that its findings cannot be generalized to all SAW as some women do face financial challenges to take part in such struggles (Anitha et. al, 2012).

The studies by Burholt and Wenger (2004), Costa-Pinto (2010), Pratt and WaltonRoberts (2005) and Sodhi (2007) all describe various empowering factors SAW use to cope with isolation and settlement challenges. The research carried by Burholt and Wenger (2004) in the UK, and Costa-Pinto (2010) in Australia sheds some light on how South Asian immigrants deal with feelings of social isolation. Burholt and Wegner (2004) explored different types of communication methods used by South Asian immigrants to connect with "transnational intergenerational relationships" (p. 153). Transnational ties are vital in eradicating feelings of social isolation and giving strength to immigrants facing settlement challenges.

The research by Costa-Pinto (2010) enlightens us on how Australian SAW used modern technology such as phones, skype, and email to stay in touch with their family and friends. This, in turn, assisted in eliminating social isolation. 
The drawbacks of Costa-Pinto (2010) study are that the accessibility and availability of such resources depends on the economic status of people using them. Not all immigrants share the same level of access to these technologies. Wider availability of these technologies in modern times makes it easier for a recent immigrant to cope with feelings of isolation in comparison to people who migrated twenty years ago.

The research conducted by Pratt and Walton-Roberts (2005), and Sodhi (2007) reflects on how mobile modernity and bicultural identity helped SAW to establish themselves successfully in Canada. Rather than highlighting the West as the savior of the East, Pratt and Walton-Roberts (2005) present the South Asian Brar family members as agents who challenge negative stereotypes about immigrants and patriarchy. The Brar family business was established by Mrs. Brar instead of her husband. Mrs. Brar provides an example of how Sikh women embody empowerment to establish themselves and their families in foreign lands. Pratt and Walton-Roberts (2005) highlight the modernity of the Brar family in a positive way describing the "modernity in creative and mobile ways that disrupt the duality of East and West" (p. 193).

A problematic aspect of the study is its positing of "modernity" in contrast with rurality with little class analysis. According to the study, rural people seem to hold strongly to patriarchal notions; whereas the study conducted by Amin (2014), concluded that there was no difference in empowerment felt by women in the rural area of Punjab compared to the urban area. Modernity in the Pratt and Walton-Roberts (2005) study relates to living lavish lifestyles, attending highclass parties and enjoying privileges of living in an upper-middle-class society.

Sodhi's (2007) study provides a different perspective; this study describes Sikh women's empowerment in the best way possible as it portrays Sikh women strengths in overcoming settlement barriers. This qualitative study involved fifteen Sikh women aged 18-67. 
Sodhi (2007) narrated how a group of women living in Halifax, Nova Scotia have overcome various settlement challenges and have established themselves successfully in Eastern Canada. These women chose cultural values which related well to their current living situation and lived authentically in both cultures. They successfully established themselves in new environments, keeping their cultural and individual identities intact and passing on strong values to their children.

This study by Sodhi (2007) focuses on the positive aspects and empowerment in terms of Sikh women's identity as it highlights the strong nature of Sikh women. Perhaps being of the same ethnic background allowed the researcher to be more aware of the strengths and weaknesses of Sikh women.

The docile and weak nature of Sikh women which we often hear about in the majority of Western studies(Abraham, 2000; Ahmad, Driver, McNally \& Stewart, 2009; Alaggia, Regehr\& Rishchynski, 2009; Anitha, 2011; Dalal, 2011; Walton- Roberts, 2007) gets challenged. We learn women are not forced to take caring roles in their houses because of patriarchy; it is their personal choice due to their understanding of their role as mothers to provide better social and cultural values to their children. Sikh women in Sodhi (2007) study are shown to think first about the betterment of their family rather than focusing on their individual needs. But since the western worldview is often entrenched in individualistic needs, these women's collective efforts are labeled as weakness and patriarchal oppression.

\section{Gaps \&Research Question}

The literature review has so far identified a few gaps; the first one being the nonexistence of literature related to Sikh Women in Ontario. 
There was specifically no research that examined factors related to the empowerment or disempowerment of Sikh Women in Ontario. This review has its limitations, as all research studies used were peer-reviewed studies carried out in India, Australia, Eastern and Western part of Canada. Important information relating to Sikh women's empowerment could have been missed since the emphasis was on academic sources of information.

Considering the aforementioned gaps in the literature, this study attempts to answer the following research question: what are the settlement experiences of Sikh Women in Ontario and specifically what empowers or disempowers them after migration? Through this question, my emphasis will be on understanding how much control Sikh women have in taking important decisions of life such as major household decisions about employment, finances, children and migrating to another country. Qualitative research focusing on narratives of Sikh women will assist in learning about life experiences of Sikh women; the research methodology is discussed in detail in the following chapter. 


\section{CHAPTER 3. RESEARCH DESIGN}

Relying on feminist narrative methodology, this MRP examines how Sikh women have been impacted by immigration and settlement and how this has affected their lives, in terms of experiences of empowerment and disempowerment. Qualitative research allows us to understand how people perceive their lives (Donna, 2008). Specifically, feminist narrative methodology is a research where, "gender is a central feature of identity and social organization, and its reproduction and organization are political/ social/ interactional process located simultaneously in individual and social structures" (D’Cruz \& Jones, 2014, p. 54).

Narratives are defined as stories that people narrate in different, "contexts ranging from formal accounts that are performed and staged, or the telling of events and feelings to friends and family, while in some cases they are relayed to researchers" (Mand, 2006, p. 1060). The narratives of participants are important to get an insight into their understanding of factors and events that influence their empowerment. "Narratives help people to make sense of their experience, construct the self, connect with others, and create and communicate meaning (Chase, 2002 as cited in Grewal, 2008, p.35). Narrative research helps us to learn a wealth of information which can be missed by other research traditions, "such as the influence of contexts" (Grewal, 2008, p. 37).Narrative research thus relates well to my research questions and theoretical framework and will help me to learn perspectives of Sikh women about empowering and disempowering factors in their lives.

\section{Participants}

Targeted Participants for this research were Sikh women between the ages of 18-70

years. Recruitment targeted participants who had migrated from India, Punjab within the last ten years and have lived in Canada, Ontario for the last five years or more. 
Exclusion criteria included Sikh women born in Canada or Sikh women who migrated to Canada from countries other than India, the reason being that women who have already settled in other countries, have faced settlement experiences prior to coming to Ontario, and the emphasis of this study is on their experiences within the Ontario context. The participants were approached through recruitment emails (Appendix A). Consent forms (Appendix B) and interview questions will be provided along with recruitment emails to participants so that they can become fully aware of the nature of the research. Both the email and the consent forms mentioned the voluntary nature of participation.

As a result of recruitment, participants in this study were Sikh women who had lived in Ontario for more than five years. The participants ranged in age from 30-40 years old. Two of the participants Harpreet and Jatinder immigrated to Canada with their parents; under family sponsorship category and one participant Sukhleen immigrated after marriage; under spousal sponsorship category (all names are pseudonyms). Two of the participants who migrated with their family came to Canada more than 14 years ago and one participant migrated to Canada 10 years ago. All the interviews were audio-recorded and took place in private rooms of a local library.

\section{Data Collection methods}

Data was collected through the use of in-person semi-structured interviews (see interview guide in Appendix C). These interviews were audio-recorded and transcribed verbatim. Voluntary participation was discussed at the initial meeting so that participants were aware of their rights and did not feel pressured in any way. The participants were made aware that refusal or withdrawal from this research will not affect my relationship with them in any way; if 
participants choose to withdraw from research within the first month; their data will be deleted immediately.

Resources were also provided to participants to deal with stressful and discomforting emotions, as participants may feel discomfort in answering questions in regards to their

settlement experience (see resource list in Appendix D). Participants were reminded that they can take breaks, choose not to answer discomforting questions or stop participating completely.

\section{Data Analysis Methods}

Thematic analysis was utilized to arrive at findings in this study. According to Boyatzis (1998) thematic analysis is a method of identifying, analyzing, and reporting patterns (themes) within data. Thematic analysis allows for flexibility as a method because it can be used with various theoretical and methodological frameworks. A "theme" in thematic analysis can be understood as, "something important about data in relation to the research question, and represents some level of patterned response or meaning within the data set" (Braun and Clarke, 2006, p. 10). For my study, I coded the transcripts, and then grouped codes together into categories, which were then grouped into common themes. My analysis attempted to arrive at themes related specifically to the empowerment and disempowerment experiences of Sikh women through a look at their settlement experiences. These themes are discussed in the following chapter.

\section{Ethical Considerations}

This study has been approved by Ryerson University's Ethics Board (see ethics clearance certificate in Appendix E) and written consent was granted by participants before starting this research. Every effort will be made to protect participants' identity. Pseudonyms were assigned 
to each participant to avoid the inclusion of personally identifiable information. Relatives and family members were assigned fake names, as well.

I was the sole person to review the information provided by the participants; when necessary, transcripts with no identifying information were shared with my supervisor. Information shared was not accessible to any other parties.

Interviews were audio-recorded on a password-protected device and then transcribed. Recordings were destroyed and transcripts will be kept in a secure locked cabinet for one year from the time of the study. Confidentiality of participants will be protected at all times. Certain information about the participants will be known to the investigator. This is needed to check if participants meet the targeted population criteria. But none of this information was stored. This information was needed only for the initial stages of the research such as to set up interviews; phone numbers and email were used. Participants were informed that data collected in this research will be disseminated in a Major Research paper. Findings of this study may also be used in future academic publications, community presentations or books. Research findings will be made available to participants via email.

Before proceeding to the presentation of findings, it is important to highlight the limitations of this study. A key limitation is that the sample size only represented a very small portion of Sikh women in Ontario. Some of the themes can be generalized but the experiences of these three women should not be taken as the experiences of all Sikh women. Every Sikh woman is a unique individual in her own ways. Sikh women's strengths and weakness might differ when compared to each other. Sikh women do have some common traits which can be attributed to their cultural values and community. The participants of this research range in age from 30-40 years. Given this, the experiences of older or younger Sikh women could be totally different 
from the participants of this research. The systemic barriers which disempower women might be similar but personal barriers might differ for each Sikh woman. 


\section{CHAPTER 4. FINDINGS AND DISCUSSION}

This chapter will discuss the findings from the interviews conducted with the participants, based on the research question. The aim of the study is to learn what empowers or disempowers Sikh women. after migrating to Ontario, Canada. In what follows, I discuss the themes that emerged from the interviews with a discussion built in every theme.

\section{Language Experiences \& Struggles with Recognition of Foreign Educational Credentials}

One common theme which emerged from all three Sikh women is the disempowering and empowering experiences with the English language. Fluency in the English language affected these Sikh women in relation to employment, education and their confidence. Harpreet revealed that not having a Canadian accent in English was challenging for her during her high school years:

I started here in high school it was very challenging; especially with the language first English was not my first language... It is one of the problems I faced while settling in Ontario. I could speak English but it was not in a Canadian accent.

The fact that she could not speak English in a similar manner to the other students, made her stand out in her class, which affected her confidence and made her feel disempowered. Jatinder recalled having a difficulty in finding a job due to the language barrier:

Finding a job was a problem due to language...in the beginning when we came here I had no job, getting a license due to language was hard. No license meant I was dependent on others for going to work and college. 
In fact, a finding that emerged from all the interviews was that although all the participants could speak English they were disempowered by their fluency level and accent. This made them stand out in a negative way when applying for jobs and while pursuing their studies.

The language barrier is a factor which is directly tied to socio-economic context as well; fluency in the English language is given more importance than women's qualifications or ability to perform the required work. A Sikh woman for whom English is a second language may not be able to speak it with the same fluency as a native speaker. Mohanty (2003) argues that immigrant women from the global South often face unjust and unfair impacts depending on their economic and social marginality (p.3). This can be seen in the disempowering struggles these three Sikh women faced, in acquiring jobs or continuing their studies in Canada. Jatinder described her struggle in seeking employment, due to credentials degradation. She shared: "The job search was hard; my credentials from back home were not recognized for jobs".

Sukhleen discussed a similar experience of how even after having a graduate degree in Computer Science from India she was having difficulty finding a job in her field. Her educational credentials were not recognized when she applied for jobs in her field:

When I came here especially with my career was a struggle. I did back home Bachelors in Computer Science and have a Masters in the same field. When I came here I was looking for a job in those fields which till date I haven't got any. My studies are considered equivalent by educational institutions and when I get it evaluated a certificate of equivalence is given. I apply for jobs and this equivalence certificate and my education is given no value. My education is still considered inferior to Canadian degrees. This is the reason even after 10 years in Canada I am still struggling to find a job in my field. 
The experience of these two Sikh women reminds us how immigrant women even after obtaining the education and qualifications to perform the job are categorized as unsuitable for employment in their fields and have to take work below their qualification to survive. Anitha, Pearson, and McDowell (201 raise a similar point about disempowering factors prevalent in the lives of South Asian Women (SAW) in England. Anitha et al. highlight how employers create hierarchies in the workforce. These authors further cite the work of Carter et al. (1996) and McDowell (2009) to reinforce how SAW get restricted in the workforce to doing manual labor:

It is within such discourses about suitability of particular bodies for different categories of work and the categorization of worker's capacities as 'good', 'bad', skilled' or unskilled that SAW, alongside other categories of migrant workers, find their options in the labour market greatly restricted. (p.761)

The workforce restrictiveness for Sikh migrant women is no different in Canada and it is evident from the Sukhleen's job search experience, shared earlier in this chapter.

When the Sikh women were asked what helped them feel empowered or get back control of their life, Harpreet responded: "After finishing the studies, getting the job helped with everything". She was referring to the fact that after overcoming the language barrier and finishing her studies in Canada, she was able to get a job as a nurse, which helped her to settle and overcome disempowering factors. Jatinder who earlier mentioned struggles with getting a license due to language barriers was able to obtain her driving license and no longer had to rely on others for transportation. She shared: "When I got a driving license, I upgraded in studies, I got a good job and financial security was there. I bought a new car and house. I felt in full control of my life". 
Sukhleen completed a short three-month course as she already had a Master's degree from India. She got a relief from doing manual labor jobs. She shared:

I would say not too long ago when my son was born I did this short course for three months. I got a job in office as an administrative clerk which I never got like five years ago. So that made me feels a little better.

These three Sikh women did not give up hope despite facing disempowering factors such as language barriers and the degradation of foreign credentials. All of them enrolled in language courses to develop their fluency in English. In addition, they also completed diploma and certificate courses in subjects of their choice; which helped them to secure better-paying jobs, recognition and personal satisfaction. What becomes clear from the Sikh women's life experiences is that discriminatory factors present in society make Sikh women feel disempowered. However, findings also demonstrate their resilience. These Sikh women's strength is commendable in fighting back these barriers. All three Sikh women have emerged victorious by pursuing their goals and fighting disempowering factors.

\section{The New Educational Environment}

Another theme which emerged from interviews was the new educational environment faced by the participants. It was not only a new country, and a new home environment for the participants; it was also a new school environment. Everything was different than what the participants were used to in their home country. Working while studying, bullying, difficulty getting required grades, stress about academic achievement, and struggles to get into professional programs were some of the disempowering factors they faced after migrating to Canada. Harpreet shared: 
It was difficult to work and study at the same time especially when you take grade 11 and grade 12 courses and when you need the required average to get admission into the college and universities. Especially the program which I wanted to take and get into was highly competitive at that time. And then facing bullying was not easy.

Harpreet continued further when asked what disempowered her:

I found it difficult when I had to get admission to the college and university because the program I wanted to get in was highly competitive. I was working as we were new immigrants and I was the oldest child in my family...I was not able to get the required average. So, I had to go through a program which basically prepared me to get into the nursing program which was my goal.

The life experience of this participant highlights the struggles for new immigrant Sikh women. Bullying is defined as, "repetitive aggression with the intention to cause harm within a dynamic imbalance between the children involved (Olweus, 1999 as cited in Vitoroulis, Brittain, \& Vaillancourt, 2016, p. 431). These authors further reinforce the fact that any form of imbalance in ethnic representation in school students is linked with higher levels of bullying experienced by minority group children. Such was the case for the first Sikh woman participant. She migrated to Canada 17 years ago and at that time she was considered a minority student in her class. Her racial identity was the target of the bullying she experienced. Bullying can affect a person both mentally and physically and causes immense stress. Sandhu and Nayar (2008) state that bullying is one, "of the pertinent socio-cultural issues that South Asian students can experience while pursuing higher education" (p. 38). These authors also quote Abbas to emphasize resiliency and strength of South Asian immigrant children. According to Abbas, 
South Asian immigrant children's participation in higher education is at a high level and these children show, "significantly better performance and retention when compared with other visible minority students" (p. 35).Hence the resilience of Sikh women in environments drenched with bullying is praiseworthy and a sign of their strength and resilience.

Along with bullying, Sikh women mentioned the challenge of working while studying simultaneously. This was not seen as a disempowering factor by them but as a means to help their family and themselves. This highlights empowerment and economic independence of Sikh women. Being the eldest in the house, one Sikh woman shared the responsibility with her parents to support the household and her own expenses. Jatinder and Sukhleen narrated similar feelings about how important it was for them to have a job and economic independence.

Reflecting on narratives of these three Sikh women, it can be said that the Sikh women interviewed are not economic dependents or subjugated to violent patriarchal norms in their houses. They are fully independent and have their own identity and goals. Sikh women manage their own expenses and did not express feeling oppressed by male members of their family. Walton-Roberts and Pratt (2005) are right in criticizing the analysis of the experiences of transnational migrant women where academic literature has been, "saturated by an ideology that locates progress, including gender equity in the West, and the most oppressive patriarchal relations in non-Western contexts." (p.173). The oppressed image of South Asian women in the western scholarship gets challenged by narratives of these three Sikh women.

\section{The Beginning years and Beyond}

Another similarity found in all three participants' lives was they all faced struggles and disempowering factors in the beginning years of their migration experiences. The first five to six years were described as being the most difficult for all the participants. 
When asked if there was anything else participants would like to share about their settlement experience in Canada, Harpreet shared:

In the beginning years, I did find it hard. I found it very challenging, getting used to the cultural difference, the Canadian system, the rules, the regulations, struggles with jobs, language barriers and new school environment; everything was difficult.

Ahmad, Driver, McNally \& Stewart (2009) in their research on South Asian women highlighted that migration definitely brings challenges for South Asian women. Cultural differences and the beginning year's hardships mentioned by this participant echoes the settlement experiences of Sikh women in Sodhi's (2007) research.To my surprise, when asked the same question Jatinder responded similarly: "In the starting first few years were difficult. Such as job search was hard, my credentials from back home were not recognized for jobs". Sukhleen echoed the same emotions when asked if there was anything else she would like to share about her settlement experience in Canada:

It was not an easy one. Especially for the first five years, I came here in 2008 and I started working with a department store doing merchandising at night shift. That was not what I thought I will work as but had to start from there.

In contrast to their beginning years of settlement, all participants described the later years and present time as being more empowering. When asked about when she felt in full control of her life after coming to Canada, Harpreet responded:

I think it is after years of experience of settling in Canada that has helped. Living here, understanding the culture, the diversity and exploring different options that were 
available for us here. After I graduated and finished my studies. I got a job, got married, bought a house and car and then I felt that ok now I am settled in Canada. So, the later years have been empowering.

Jatinder had this response to the same question:

When I got a driving license, I upgraded in studies, I got a good job and financial security was there. I bought a new car and house. I felt in full control of my life. It is all become easy now.

Similarly, Sukhleen responded:

The first five years were hard and after that the rest of the years have been ok. One thing which still bothers me though is not being able to get the job in my field. I have done a short course in software testing. It is just that I do not get enough time due to children to be able to concentrate on my career yet. May be once they are little older I will be able to find job in my field.

This participant's feelings depicted how, like the others, she found her beginning years hard and later years less disempowering. However, she still feels disempowered due to the lack of a proper career. This participant does not have her parents in Canada. Due to this, she and her husband are busy taking care of their two young children and balancing their lives between work and home. Sodhi (2007) mentions this as a difficulty for the Sikh women of Maritime society in Eastern Canada. She shares: "This was a major hardship first-generation Sikh women endured; that is, balancing both current work and home responsibilities. Even while living in smaller communities with limited resources and less community events, these women were still able to child-rear and transmit cultural values to their children in their new homeland"(p.292). 
As Sodhi (2007) notes, Sikh women know how to change disempowering situations into empowering ones. The same hope and strength can be seen in the narrative of the third Sikh woman as she hopes that when her children start going to school fulltime she can focus on her career aspirations. This shows her strength of character. She is able to care for her family and to not give up in the face of challenges. She is hopeful and willing to continue her struggle to achieve her dreams.

Another factor that was seen as empowering was family support. For Harpreet and Jatinder the support provided by their families became their strength. These two Sikh women had migrated with their parents and siblings. Both of them mentioned familial support as one of the most empowering factors while the third participant felt disempowered due to the absence of familial support in Canada. Harpreet mentioned the importance of taking her parents' advice when she made important decisions in life. She shared:

I would consult with my parents and would ask for their advice, their decisions, and their suggestions. Because they have years of experience and their advice and support is valuable in my life.

When asked about how her overall settlement experience in Ontario felt, Jatinder replied: "My settlement experience was good because my family supported me whenever I had difficulty”. According to her, the challenges she faced did not matter or did not make her lose hope because her family supported her whenever she faced any difficulty in life. Sukhleen feelings of isolation were evident when she was asked about some of the problems she faced while settling in Ontario. She stated: "I miss my family a lot". 
Abraham (2000) has touched on the topic of isolation as a disempowering factor in her research on immigrant women. According to her research, a woman can experience isolation when she does not have friend and family support in a foreign country (p. 231).

In the life of Sukhleen, isolation from the support of loved ones and the absence of family became a disempowering factor. Sukhleen further shared how raising two small children without family support is hard: "I and my husband work alternate schedules and in the time when both our work schedules overlap we have struggled with finding childcare". This participant reminisced with a smile on her face about the time when her mother and mother in law came to help her before and after her child delivery. She shared:

My mom came and helped me with my deliveries and when my mother in law came she took care of my children after delivery for some time. That was the only time when I had some relaxation or free time for myself... These days I don't have help, so I start early in the morning around 6 am and go to bed around $10 \mathrm{pm}$. In all these hours, I am busy working or taking care of children.

This Sikh woman felt she had to struggle a lot due to the absence of her family. When asked what could have made it better for her to settle smoothly or feel empowered she replied:

If I had my family here to help me and support me, I would have been able to have some time for myself and could upgrade my studies earlier and would have been able to get a good job...I see a lot of people have their families around and these families can support them a lot. So, it would have been a different and better experience if I would have had my parents here to support me. I could get some free time for myself. 
This participant's statement is validated by the outcome of the presence of family support for Harpreet and Jatinder. These two participants were able to complete a Bachelor's degree and Diploma due to their family's support during difficult and challenging times. Owing to lack of family support; Sukhleen only managed to complete a three-month short course and still struggled to obtain a position in her Information Technology field, while the other two Harpreet and Jatinder found jobs in their field. I found that the women I interviewed had similar experiences to the Sikh women Sodhi (2007) interviewed in her study. Sodhi reflects:

Amongst other difficulties upon migrating to eastern Canada included sacrificing career aspirations...Even though these women were intelligent and highly educated, first generation Sikh women chose to stagnate in their profession in order to provide a better life for their family. (p. 291)

This highlights the socio-economic and discriminatory factors which exist in Canadian society; resulting in contributing to the disempowerment of Sikh women. Government support for child care is limited to families in Ontario. The mothers of young children often have to leave aside their career goals to take care of their family as reflected in Sodhi's (2007) research.

Further evidence highlighting the positive outcomes of family support for these women, comes through the narratives from the Sikh women, especially regarding spousal companionship and support in their settlement experiences. All the women shared how after marriage they made every important household decision together with their husbands. When the decisions concerned only themselves, the women made them solely on their own and their husbands did not interfere with the choices made. When asked who makes important decision in her household, Harpreet replied: "I basically take my own decisions in regard to my finances and job. After I got married, 
now I live with my husband and basically, now both of us look after household finances". Harpreet further shared:

If anything comes in the household I would discuss it with my husband and we take any decisions in the household together if it involves both of us... We enjoy each other's company; we do everything together, watch movies, go for vacation and even take swimming classes together.

This Sikh woman's narrative depicts her married life being full of happiness and togetherness. Nowhere in her narrative can be found any trace of marital discord. Hence it would not be wrong to say that she views her husband as her strength and as one of the empowering support factors in her life.Jatinder gave a similar answer to the question regarding decisions about important household matters:

Nobody controls my life. My husband gives me advice when I ask for it. We both share the responsibility of any decisions regarding our household. We talk to each other and then decide what needs to be done. And anything personal I take my own decisions.

She further added that for relaxation she likes spending time with her husband and family: "I go to the spa, watch movies with my friends and family and go on vacations with my family and my husband". Sukhleen shared a similar narrative of making household decisions together with her husband. She replied:

I do not take decisions by myself only. Our decisions regarding household are taken collaboratively. It is like we both take decisions together after advice from each other. He always asks me what we are going to do and then our decisions are taken by both of us. 
And when asked about the activities she does for her relaxation, she shared that she likes going on vacation with her husband and her children: "We just took a short vacation. We went to Florida in February".

In all of the three Sikh women's narratives there were no instances of domestic violence. When participants spoke of their husbands they would smile and share their husbands' being a vital part of their lives. They collaborated on important household decisions together and even in relaxation activities, the husband's opinion was valued. Hence the domestic violence instances mentioned in western literature(Abraham, 2000; Ahmad, Driver, McNally \& Stewart, 2009; Alaggia, Regehr \& Rishchynski, 2009; Anitha, 2011; Dalal, 2011; Walton- Roberts, 2007) cannot account for experiences of all South Asian women or Sikh women and cannot be used to define Sikh women in general.

South Asian women migrants are stereotyped as docile and being dependent on the male members of their family in western literature. Their strong identity often gets confined within the constraints of domestic violence notions in the media and the scholarship. Many of the journal articles reviewed especially those by Abraham (2000), Ahmad, Driver, McNally, and Stewart (2009), Alaggia, Regehr, and Rishchynski (2009), Anitha (2011), Dalal (2011), and WaltonRoberts (2007) highlighted South Asian women's identity as being suppressed by domestic violence. Although life experiences of participants in these studies cannot be neglected, these experiences also cannot be used to define experience of Sikh women in general.

The narratives of the three Sikh women in the study help us understand the systemic and linguistic barriers which constrain their empowerment. Sikh women are resilient and fight strongly against disempowering factors. They look forward to finding opportunities to establish themselves successfully. The self-empowering stories of Sikh women in this research resonate 
well with the empowerment experiences of Sikh women discussed in other studies (Amin, 2014; Anitha, Pearson, \& McDowell, 2012; Burholt \& Wenger, 2004; Costa-Pinto, 2010; Gupta \& Yesudian, 2006; Pratt \& Walton-Roberts, 2005; Sodhi, 2007).

The studies by Amin, 2014; Anitha, Pearson, \& McDowell, 2012; Burholt \& Wenger, 2004; Costa-Pinto, 2010; Gupta \& Yesudian, 2006; Pratt \& Walton-Roberts, 2005; Sodhi, 2007 showed similar resilience of Sikh women towards disempowering factors. Taking the findings of my study into account, I will now discuss implications for social work. 


\section{CHAPTER 5. IMPLICATIONS AND CONCLUSION}

The Sikh women in this research study used their personal life experiences to discuss what empowered or disempowered them after migrating to Ontario, Canada. Their firsthand accounts helped navigate answers to the following research questions: How was the overall settlement experience of Sikh women in Ontario, Canada? When did Sikh women feel disempowered? What were some of the problems Sikh women faced while settling in Ontario? Who made important decisions in their household about employment, finances and children? Which activities helped them to feel relaxed? Did they feel in full control of their life and empowered?

Language barriers, the new educational environment and hardships in the beginning years presented struggles.Evidence of their empowerment can be seen in how they fought these barriers and emerged victorious. Instead of looking back, all these participants choose to look forward; they looked at life beyond their struggles and felt that they were able to successfully establish themselves in Canada. Building on these findings, this chapter will discuss the implications for social work practice with Sikh women. I also include suggestions offered by the Sikh women to help other women overcome disempowering factors in their lives and to support Sikh women migrants.

\section{Implications for Social Work Practice}

Social workers in various settlement agencies can benefit from understanding the resilience of new migrant women. Specifically, this research can assist in better understanding Sikh women's experiences; and provide insight into some of the initial settlement barriers Sikh women face after migrating to Canada. We can learn what actions are taken by them to overcome these barriers. 
The narratives of Sikh women in this research mirror to some extent the feelings and experiences of other Sikh women in Canada, as noted throughout this paper. If independence and employment hold importance for Sikh woman; so does the value of family and culture; and Sikh women might put a hold on their career aspirations to support their families. Settlement social workers can better understand the importance of culture and family support in the life of Sikh women; which would assist workers in providing culturally supportive services to Sikh women.

Findings of this study can also help challenge some of the negative myths about Sikh women being weak or docile and being impacted heavily by domestic violence. Settlement workers should thus be mindful of generalizing such negative experiences to all Sikh women. Not every Sikh woman's life experience in Canada is same. Greater Toronto Area has a high ratio of Sikh population; and this research can aid settlement workers in understanding challenges specific to women in the Punjabi community.

It is crucial for social workers to understand that Sikh women should not be viewed as “dependent". Some Sikh women might not speak English with as much fluency as others who may have had a longer exposure to the language, or for whom English is not a secondary language. However, this does not mean that they are "uneducated". In fact, as seen by the participants in this study, these women accord high importance to education and financial independence. They feel proud of being the person on whom others can rely for support. The Sikh women in this research also suggested that educational programs should be offered at low cost to new immigrants. This would help Sikh women to feel empowered in the earlier settlement years in Canada. Thus, settlement workers can advocate for development of educational programs which will support Sikh women in their education endeavours. 
In addition, community development workers can provide recommendations to local municipal governments on what sort of programs can be of interest to Sikh women in their local communities.

\section{Future Research}

Further research could be conducted to understand empowering and disempowering factors in the lives of Sikh women. A larger sample size would help to determine the diversity of narratives within a wide range of participants in terms of experiencing empowerment or disempowerment. Research could also be conducted with Sikh women who might have migrated on their own instead of being sponsored by their family members. Independent migrant Sikh women's life experience might differ from other Sikh women. A more variable sample size might give different findings. Transnational migration and its impact on Sikh women's lives could also be researched in the future. As well, the ways education impacts empowerment and the financial security of Sikh women could be further explored. Discriminatory factors such as racism and bullying can be further researched to find how they affect the success rate of Sikh women in fields of employment and education.

\section{Conclusion}

In conclusion, this research study suggests that the three Sikh women interviewed have different experiences than those of South Asian women depicted in many western studies. Sikh women need to be seen as unique individuals with resilience and aspirations to lead a successful

life. After migrating to Canada, Sikh women do face many challenges; but these are often related to external societal factors. For example, socio-economic factors affect the life of Sikh women drastically, asvalidated by the narratives of Sikh women in this research. 
Sikh women experience language barriers, a new school environment, pressure to get required grades for professional programs, culture shock, differing cultural values and discrimination in the employment field. All these factors could disempower them in their new environment. However, despite all these challenges, Sikh women do not lose hope and work hard to achieve their goals and establish themselves successfully as resilient and independent women. They do not neglect their families to get ahead in life; their families are their strength and empower them with much needed support. As I reflect on the narratives of the women I interviewed, I believe that Sikh women are empowered and do not sit back in face of adversity as they see the importance of sailing through rough storms to reach their destination. 


\section{APPENDICES}

\section{Appendix A}

\section{Recruitment E-mail}

To whom it may concern:

My name is Rajinder Virk, and I am a Master of Social Work student at Ryerson University's School of Social Work. I am currently completing a major research paper under the supervision of Dr. Samantha Wehbi, on settlement experiences of Sikh women after they immigrate to Canada from Punjab, India. I am particularly interested in learning what empowers (having full control over life major decisions) or disempowers (not having full control over life major decisions) Sikh women.

I am hoping you might be interested in participating in this study yourself. If you feel you are not interested but someone you know might be interested in participating, please free to pass on this letter. I am seeking volunteers who are between the ages of 18 and 70 who have lived in Ontario for last five years or more.

The purpose of this study is to learn what factors inhibit Sikh women's empowerment. I am interested in hearing how Sikh women have been impacted by immigration and settlement and how it has affected their lives. What steps did Sikh women take to face these struggles? Participation in this research study is totally voluntary and you can choose to stop participating or withdraw from this research within the first month of participation. Participants in the study will be provided with a $\$ 10$ Tim Horton's gift card as a small token of appreciation and will be reimbursed for public transportation if needed (2 local transit bus tickets). Please do not feel obligated to participate in this study. Your choice of whether or not to participate will not 
influence your future relations with Ryerson University or the investigator Rajinder Virk, or her supervisor, involved in the research.

Please see the attached interview questions with this email. These questions will help you to become more familiar with what will be asked in the interview and decide if you would feel comfortable to participate or not.

I appreciate the time you took to read this email. Please forward this email if you wish to do so.

If you need further information about this study or would like to speak with me instead of sending an email. Please do feel free to contact me at the contact information provided below.

Thank you for your time and consideration.

Sincerely

Rajinder Virk (Student)

School of Social Work at Ryerson University

r1virk@ryerson.ca 


\section{Appendix B}

\section{Consent Form}

\section{Ryerson \\ University}

\section{Graduate Studies}

\section{School of Social Work \\ Faculty of Community Services \\ Consent Form}

You are being invited to participate in a research study. Please read this consent form so that you understand what your participation will involve. Before you consent to participate, please ask any questions to be sure you understand what your participation will involve.

What empowers or disempowers Sikh women after migrating to Ontario, Canada?

INVESTIGATORS:This research study is being conducted by Rajinder Virk, supervised by Dr. Samantha Wehbi, from the School of Social Work, Faculty of Community Services at Ryerson University.

If you have any questions or concerns about the research, please feel free to contact Rajinder Virk at r1virk@ryerson.ca or Samantha Wehbi at swehbi@ryerson.ca

PURPOSE OF THE STUDY: This study is designed to explore the settlement experiences of Sikh women in Ontario, Canada. The main purpose is to learn what empowers or disempowers Sikh women after migration? Participants who identify as Sikh women and are between the ages of 18-70 and have lived in Ontario, Canada for last five years or more can participate in this study. This study will be conducted with 3 participants. This study is being conducted by a graduate student as a requirement for completion of their degree. Findings of this study may be used in future academic publications, community presentations or books. 
WHAT YOU WILLBE ASKED TO DO:If you volunteer to participate in this study, you will be asked to do the following things:

- Participate in a one on one interview session.

- You will be asked to share your settlement experiences of migrating to Ontario, Canada.

- The experiences of having or not having full control over life major decisions will be explored. Such as decisions related to work, finances, self-care and children.

- The expected duration of the interview is one hour; the expected meeting location will be local library rooms which provide completed aural and visual privacy.

- You can expect interview questions such as the following:

How was your overall migratory experience to Ontario, Canada?

What helped you to take full control of your life once you started living in Ontario, Canada?

What were some of the problems you encountered while settling in Ontario?

- Research findings will be made available to you via email, mail or pick up whichever method is selected by the participants.

POTENTIAL BENEFITS: This study might not provide any direct benefit to you, but it may add to existing social work literature. Findings may help settlement agencies in understanding the needs of Sikh women after migrating to Canada and what challenges are faced by them. This, in turn, may help settlement workers to provide culturally competent support to Sikh women. This study may help challenge some of the negative myths about Sikh women. However, the researcher cannot give a guarantee that you will receive any personal benefits from participating in this study.

WHAT ARE THE POTENTIAL RISKS TO YOU AS A PARTICIPANT: Participation in this study is low risk. You may feel discomfort when answering questions in regards to your 
settlement experience. For some, participants, sharing these experiences may be difficult and may result, in the feeling of upset or discomfort. Participants are reminded they can take breaks, choose not to answer discomforting questions or stop participating completely. Resources will be provided to you to deal with stressful and discomforting emotions.

CONFIDENTIALITY: Every effort will be made to protect your identity. Pseudonyms (fake names) will be assigned to you. Other potential identifying information example names of relatives or family members will be assigned fake names as well. The information you provide will only be reviewed by the researcher and if necessary written transcripts with no identifying information will be shared with their supervisor. Information shared will not be accessible to any other parties. Interviews will be audio-recoded on a password protected device and then transcribed. Recordings will then be destroyed and written transcripts kept for one year from the time of the study. Written transcripts will be kept in a secured locked cabinet.Your direct words may be used in some community presentations but care would be taken to make sure your names do not get associated with your words. I will ensure that no potentially identifying direct quotations will be used and neither would use any quotations or words that you ask me not to use.

\section{COMPENSATION FOR PARTICIPATION:}

A ten dollar Tim Horton's gift card is being provided as recognition of your time and efforts. COSTS TO PARTICIPATION: Reimbursement of up to two local transit bus tickets may be provided at the request of the research participant. Other cost of participation including parking or gas will not be covered.

\section{VOLUNTARY PARTICIPATION AND WITHDRAWAL:}


Participation in this study is completely voluntary. You can choose whether to be in this study or not. If any question makes you uncomfortable, you can skip that question. If you choose to stop participation, you may do so within the first month and you will still be given the incentives and reimbursements described above. If you choose to stop participation within the first month, you may also choose to not have your data included in the study. Your choice of whether or not to participate will not influence your future relations with Ryerson University or the investigator Rajinder Virk, or her supervisor, involved in the research.

QUESTIONS ABOUT THE STUDY: If you have any questions about the research now, please ask. If you have questions later about the research, you may contact.

\author{
Rajinder Virk \\ Investigator, MSW Candidate \\ r1virk@ryerson.ca \\ Samantha Wehbi \\ Supervisor \\ swehbi@ryerson.ca
}

416-979-5000 ext. 6221

This study has been reviewed by the Ryerson University Research Ethics Board.

If you have questions regarding your rights as a participant in this study please contact:

Research Ethics Board

C/O Office of the Vice President, Research and Innovation

Ryerson University

350 Victoria Street

Toronto, ON M5B 2K3 
416-979-5042

rebchair@ryerson.ca

\section{What empowers or disempowers Sikh women after migrating to Ontario, Canada?} CONFIRMATION OF AGREEMENT:

Your signature below indicates that you have read the information in this agreement and have

had a chance to ask any questions you have about the study. Your signature also indicates that you agree to participate in the study and have been told that you can change your mind and withdraw your consent to participate within the first month of participation. You have been given a copy of this agreement.

You have been told that by signing this consent agreement you are not giving up any of your legal rights.

Name of Participant (please print)

Signature of Participant

Date

I agree to be audio-recorded for the purposes of this study. I understand how these recordings will be stored and destroyed.

Signature of Participant

Date

I would like to receive a copy of the study's findings by this method or at this address: 


\section{Appendix C}

\section{Interview Guide}

First of all, thank you for participating in this study. Please do inform me if you feel uncomfortable with any question. There is no pressure to continue; you have the choice to take a break or withdraw from this study anytime.

1).Please share why did you decide to come to Canada?

2).Please share how was your overall settlement experience in Ontario, Canada.

3).Tell me about a time after coming to Canada when you felt disempowered.

4). Tell me about a time after coming to Canada when you felt you had full control over taking life major decisions? What do you think helped you to feel in full control?

5).Please share what were some of the problems you faced while settling in Ontario.

6).Tell me about a time when you took important decisions in your household about employment, finances and children?

7).Tell me about a time when you took care of yourself and did activities which helped you to feel relaxed.

8). Please share if you feel you are in full control of your life and no one has control over your decisions or choices you make in life.

9). Is there anything else you would like to share with me about your settlement experiences in Ontario? 


\section{Appendix D}

\section{Resources for Participants}

Please see below list of three organizations which provide support for women in various ways. If you feel stressed or have anxiety or any feelings of discomfort due to participating in this study, or otherwise, please consider seeking support from these agencies which offer free counselling sessions and other support programs. Punjabi Community Health Services specifically tailor services to people belonging to the Sikh Community. So if you feel you need support in Punjabi language, this agency has expertise, in providing culturally competent services for Sikh women.

\section{Punjabi Community Health Services (PCHS):}

Punjabi Community Health Services (PCHS) is a pioneer community based not for profit, charitable organization fulfilling needs of the diverse communities for the past 26 years by providing services in the areas of addictions, mental health, geriatric, health promotion, domestic violence, parenting, settlement and services for women, children and youth. This community agency is known for its Integrated Holistic Service Delivery Model. Working hours vary so please call before going:

Their offices are located at:

Brampton

Brampton Office - 50 Sunny Meadow Blvd, Suite \# 201, Brampton, ON L6R 0Y7

Phone Number :( 905) 677-0889

Mississauga

Malton Office - 2980 Drew Road, Unit \# 241, Mississauga, ON L4T 0A7

Phone Number :(905) 677-0889

\section{Family Services of Peel:}

This community agency offers free, private and confidential Walk-In Counselling Service without having to book an appointment. Their staff is professionally trained and has qualified 
multicultural staff for support, advocacy and referrals to other available services. Immediate support is available for anyone who is:

Experiencing a crisis

Requiring immediate support

Seeking information about specific services in the community

Requiring advocacy and referrals

FREE Walk-In Counselling Services are provided at Family Services of Peel's

Mississauga office (151 City Centre Drive, Suite 501).

Please see the specific times below:

Mississauga Every Wednesday 12:00pm to 8:00pm and Every Saturday

(Excluding holiday weekends) 9:00am to 12:00pm

Address: 151 City Centre Dr \#501, Mississauga, ON L5B 1M7

Phone :( 905) 270-2250

Hours: Open today $\cdot 9 \mathrm{AM}-9 \mathrm{PM}$

\section{Canadian Mental Health Association - Peel Branch:}

CMHA Peel offers time-limited therapeutic intervention. Their mental health counsellors will assess and offer anywhere between one and up to eight counselling appointments; the number of sessions will be assessed based on clinical need. Where necessary, referrals for on-going counselling will be made to other community service providers.

A person, concerned family member, and/or a service provider can contact Central Intake at 905$451-2123$.

Translation services are also provided:

This organization is located at $314-7700$ Hurontario Street, Brampton, ON, L6Y 4M3

Phone number: (905) 451-2123 


\section{Appendix E}

\section{Ethics Clearance Certificate}

\section{Ryerson University}

\section{Research Ethics Board}

To: Rajinder Kaur Virk Social Work

Re: REB 2016-443: What empowers or disempowers Sikh women after migrating to Ontario, Canada?

Date: February 15, 2017

Dear Rajinder Kaur Virk,

The review of your protocol REB File REB 2016-443 is now complete. The project has been approved for a one year period. Please note that before proceeding with your project, compliance with other required University approvals/certifications, institutional requirements, or governmental authorizations may be required.

This approval may be extended after one year upon request. Please be advised that if the project is not renewed, approval will expire and no more research involving humans may take place. If this is a funded project, access to research funds may also be affected.

Please note that REB approval policies require that you adhere strictly to the protocol as last reviewed by the REB and that any modifications must be approved by the Board before they can be implemented. Adverse or unexpected events must be reported to the REB as soon as possible with an indication from the Principal Investigator as to how, in the view of the Principal Investigator, these events affect the continuation of the protocol.

Finally, if research subjects are in the care of a health facility, at a school, or other institution or community organization, it is the responsibility of the Principal Investigator to ensure that the ethical guidelines and approvals of those facilities or institutions are obtained and filed with the REB prior to the initiation of any research.

Please quote your REB file number (REB 2016-443) on future correspondence.

Congratulations and best of luck in conducting your research.

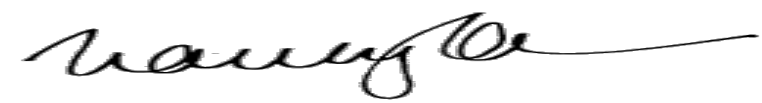

Dr. Nancy Walton, $\mathrm{PhD}$

(A) Co-Chair

Ryerson Research Ethics Board 416-212-4952 nwalton@,ryerson.ca

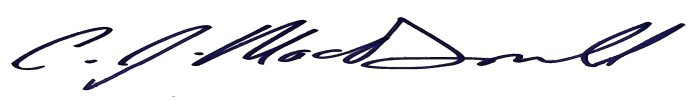

Dr. Chris Macdonald, $\mathrm{PhD}$

(A) Co-Chair, Ryerson Research

Ethics Board 416-979-5000 ext. 6903

chris.macdonald@ryerson.ca 


\section{REFERENCE LIST}

Abraham, M. (2000). Isolation as a form of marital violence: The South Asian immigrant experience. Journal of Social Distress and the Homeless, 9(3), 221-236.

Ahmad, F., Driver, N., McNally, M. J., \& Stewart, D. E. (2009). "Why doesn't she seek help for partner abuse?" an exploratory study with South Asian immigrant women. Social Science \& Medicine, 69(4), 613-622.

Alaggia, R., Regehr, C., \& Rishchynski, G. (2009). Intimate partner violence and immigration laws in Canada: How far have we come? International Journal of Law and Psychiatry, 32(6), 335-341.

Aksornkool,N., Digheu. A., Horsmann.J., Lazo. L.,Aonuevo-Medel,C., Bochynek, B., Stromquist-P.,\&N. Zuñiga.M. (1993). Women, Education and Empowerment: Pathways towards Autonomy (UIE Studies.5). Hamburg: Robert Seemann u Neumann-Reichard.

Amin, S. (2014). Social freedom among women in Punjab. Indian Journal of Health and Wellbeing, 5(6), 745-747.

Anitha, S. (2011). Legislating gender inequalities: The nature and patterns of domestic violence experienced by South Asian women with insecure immigration status in the United Kingdom. Violence Against Women, 17(10), 1260-1285.

Anitha, S., Pearson, R., \& McDowell, L. (2012). Striking lives: Multiple narratives of South Asian women's employment, identity and protest in the UK. Ethnicities, 12(6), 754-775.

Boyatzis, R. E. (1998). Transforming qualitative information: Thematic analysis and code development. Thousand Oaks, CA: Sage. 
Burholt, V., \& Wenger, G. C. (2004). Migration from South Asia to the United Kingdom and the maintenance of transnational intergenerational relationships. Annual Review of Gerontology \& Geriatrics, 24, 153-176.

Braun, V., \& Clarke, V. (2006) Using thematic analysis in psychology. Qualitative Research in Psychology, 3 (2). pp. 77-101.

Costa-Pinto, S. (2014). Making the most of technology: Indian women migrants in Australia. International Migration, 52(2), 198-217.

Dalal, K. (2011). Does economic empowerment protect women from intimate partner violence? Journal of Injury \& Violence Research, 3(1), 35-44.

D’Cruz, H., \& Jones, M. (2014) Social Work Research in Practice. London: Sage Publications Limited.

Donnah, H. (2008).Research Paradigms (PowerPoint Slides).Retrieved fromzimmer.csufresno.edu/ donnah/Research\%20Paradigms.ppt

Grewal, I.,\& Kaplan, C. (1994). Scattered hegemonies: Postmodernity and transnational feminist practices. Minneapolis: University of Minnesota Press.

Grewal, I., \&Kaplan, C. (2000). Postcolonial studies and transnational feminist practices. Journal of Postcolonial Studies, 5(1), 1-3.

Grewal, N. (2008). In her words: Five Punjabi women discuss experiencing depressive symptoms, coping strategies, and seeking help.(Unpublished Master's thesis).California State University, Fresno.

Gupta, K., \& Yesudian, P.P. (2006).Evidence of women's empowerment in India : a study of socio-spatial disparities. GeoJournal, 65(4), 365-380. 
Kaur, G. (2004, May). Guru Granth Sahib and empowerment of women. Paper presented at the International Sikh Conferences, Walnut, CA.

Mand, K. (2006). Gender, ethnicity and social relations in the narratives of elderly sikh men and women. Ethnic and Racial Studies, 29(6), 1057-1071.

Mohanty, C. T. (2003). Feminism without borders: Decolonizing theory, practicing solidarity. London: Duke University Press.

Ng, C. F., \& Northcott, H.C (2009). The Ethnic and national identity of South Asian immigrant seniors living in Edmonton, Canada. Canadian Ethnic Studies Journal, 41(3), 131-156.

Sandhu, J. S., \& Nayar, K. E. (2008). Studying the sikh diaspora: First-year university experience of punjabi sikh students. Sikh Formations, 4(1), 33-46. doi:10.1080/17448720802075421

Singh, I. J. (2004, May). What Sikhism says about gender and sex. Paper presented at the International Sikh Conferences, Walnut, CA.

Sodhi, P. (2007). Respecting the east, embracing the west: A tribute to the women of the Maritime Sikh Society. Journal of International Women's Studies, 9(1), 285-296.

Vitoroulis, I., Brittain, H., \& Vaillancourt, T. (2016). School ethnic composition and bullying in canadian schools. International Journal of Behavioral Development, 40(5), 431-441. doi:10.1177/0165025415603490

Walton-Roberts, M., \& Pratt, G. (2005). Mobile modernities: A south asian family negotiates immigration, gender and class in Canada. Gender, Place \& Culture, 12(2), 173-195.

Walton-Roberts, M. (2007). Weak ties, immigrant women and neoliberal states: Moving beyond the public/private binary. Geoforum, 39(1), 499-510. 